\title{
105. The impact of nano-silica type, size and consumption percent on properties of cement mortar
}

\author{
Khodabandehlou Ashkan', Saleh Haghgou Vahid ${ }^{2}$ \\ Faculty of Engineering, Department of Civil Engineering, Urmia Branch, \\ Islamic Azad University, Urmia, Iran \\ ${ }^{1}$ Corresponding author \\ E-mail: ${ }^{1}$ ashkan72@rambler.ru, ${ }^{2}$ vahid.s.haghgou@gmail.com
}

Received 4 June 2016; accepted 26 June 2016

DOI http://dx.doi.org/10.21595/jme.2016.17325

\begin{abstract}
Regarding the performance of Nano-silica in cement based materials such as cement paste, mortar and concrete there are different outcomes revealed by researchers that fluctuates around significant increase or decrease in resistance of due materials. In the present research the impact of different kinds of Nano-silica whether powder or colloids form and special plane with 80 to $500 \mathrm{~m} 2 /$ gr on characteristics of new and hardened mortar has been investigated. The results indicated that Nano-silica contributes to dramatic decrease in performanceality. As such, to compensate the loss one needs to use super plasticizer. Using Nano-silica increases pressure resistance regarding control mortar and in some cases the level of pressure is more than mortar containing silica fume. Also the majority of increase in Nano-silica resistance takes place during seven days. The size of Nano-silica particles in this research was evaluated by Transmission Electron Microscopy (TEM).
\end{abstract}

Keywords: nano-silica, size of particles, cement, TEM.

\section{Introduction}

With regard to the successful use of silica fume with purity of 90 percent and special plane about $20 \mathrm{~m}^{2} / \mathrm{gr}$ as a super pozzolana in production of high-performance concrete (HPC) and high-strength concrete, and on the other hand the availability of Nano-silica materials with 100 percent purity and special plane of $60 \mathrm{~m}^{2} / \mathrm{gr}$ to about $600 \mathrm{~m}^{2} / \mathrm{gr}$, investigating the possibility of usage of Nano-silica materials in improving the characteristics of cement based materials has changed into one of the most interesting field of research in recent years all over the world. In different inquiries about the impact of Nano-silica on the characteristics of cement based materials including cement paste, mortar and concrete the results contributed to different outcomes and sometime contradictory ones. In investigating the impact of Nano-silica on cement paste conducted by Shih and et al optimum consumption percent was reported $60 \%$. Consumed Nano-silica in the same research was colloid with $40 \%$ silica in $20 \mathrm{~nm}$ size and in cement weigh values of $0 / 2,0 / 4,0 / 6$ and $0 / 8$. It was reported that the maximum increase in resistance in optimum consumption percent in contrast to the control group was about $60 \%$ in 14 days. In other ages this value decreased and in 56 days reached $43 \%$. Lin and et al used powder Nano-silica in $10 \mathrm{~nm}$ size and special plane of $670 \mathrm{~m}^{2} / \mathrm{gr}$, with cement weigh values of 1,2 , and 3 in paste. The results indicated that the optimum value of Nano-silica is in 3 percent and the rate of resistance increase in contrast to control group shows $6 \%$ in 7 days and $4 / 5 \%$ in 28 days. Jo and et al reported that the impact of Nano-silica materials in its powder form with particle size of $40 \mathrm{~nm}$ and special plane of $60 \mathrm{~m}^{2} / \mathrm{gr}$ in consumption rates of 3,6 , and 10 with $12 \%$ cement weigh value showed the maximum resistance increase in 7 days with $12 \%$ usage of Nano-silica contributing to $177 \%$ value in contrast to control mortar while the maximum value in silica fume took place in $15 \%$ and contributed to $42 \%$. In the 28 day the resistance increase in contrast to control group regarding Nano-silica contributed to decrease up to $169 \%$ and increase in silica fume up to $48 \%$. In another study regarding the impact of Nano-silica on mechanical characteristics of cement mortar it was reported that Nano-silica powder with special plane of $160 \mathrm{~m}^{2} / \mathrm{gr}$ and size of $15 \mathrm{~nm}$ was substituted in $10 \%$ with cement up to 5.3 amount of material. In the same study it was observed that resistance 
increase in $10 \%$ usage in 7 days is $20 \%$ and in 28 days is $26 \%$ in contrast to control mortar. The result of the study showed differences regarding the optimum consumption rates contrasting with normal mortar, and also resistance increase percentage in different ages in comparison to previous study results. Khanzadi and et al investigated the impact of Cembinder 8 Nano-silica - a kind of colloid Nano-silica with special plane of $80 \mathrm{~m}^{2} / \mathrm{gr}$ - in usage percent of $2 / 5,5,7 / 5$, and 10 in cement mortar. The results indicated resistance increase in $10 \%$ of usage of Nano-silica. In the study conducted by Sadr Momtazi and et al the impact of Nano-silica with size of $50 \mathrm{~nm}$ in its colloid form in 1, 3, 5, 7, and $9 \%$ of cement substitution on cement characteristics was investigated. Nano-silica optimum consumption percent was reported $7 \%$ and increase in usage showed no influence regarding pressure resistance. Ramezanianpour and et al also studies the impact of application of colloid Nano-silica - Cembinder 8 - in concrete. Maximum resistance increase was reported $7 / 5 \%$ in 3 days and total value of $38 \%$ in contrast to control concrete. The increase was declined in higher ages reaching $14 \%$ in 90 days in contrast to control concrete. According to the results of the same study $7 / 5 \%$ of Nano-silica is regarded as the optimum consumption percent contributing to increase in consumption value. The impact of powder Nano-silica in size of $10 \mathrm{~nm}$ and special plane of $640 \mathrm{~m}^{2} / \mathrm{gr}$ on concrete resistance was reported by $\mathrm{Li}$ and et al. They reported that Nano-silica was added to concrete with 1 and 3 percent of cement weigh value to the concrete. It was observed that the value of optimum usage was 1 and pressure resistance in contrast to control concrete showed $12 \%$ in 28 days. Above mentioned studies show great difference in obtained results regarding the impact of Nano-silica application on cement based materials' resistance. Optimum consumption rates were reported from about $6 \%$ up to $10 \%$. Impact over the resistance in contrast to control group was reported up to $170 \%$ increase and even in some cases decrease. Also above mentioned results indicated that despite the fixed characteristics of silica fume, Nano-silica is produced with various size and special plane degrees from about $60 \mathrm{~m}^{2} / \mathrm{gr}$ up to more than $600 \mathrm{~m}^{2} / \mathrm{gr}$. The present study was conducted in order to reveal the impact of Nano-silica particle size and special plane features on improving the mechanical characteristics of Portland cement mortars. To do so the impact of different usages of values and ages of powder and colloid Nano-silica with different special planes in a laboratory program were determined and compared with the performance of silica fume as a known super pozzolana.

\section{Laboratory program}

\subsection{Materials in use}

\subsubsection{Cement}

Portland cement, type 425-1 was used that its chemical analysis is illustrated in Table 1.

Table 1. Chemical analysis of cement and silica fume

\begin{tabular}{|l|c|c|c|c|c|c|c|c|c|c|}
\hline \multirow{2}{*}{ Percent } & \multicolumn{10}{|c|}{ Chemical compound } \\
\cline { 2 - 11 } & $\mathrm{CaO}$ & $\mathrm{SiO} 2$ & $\mathrm{Al} 2 \mathrm{O} 3$ & $\mathrm{Fe} 2 \mathrm{O} 3$ & $\mathrm{MgO}$ & $\mathrm{SO} 3$ & $\mathrm{Na} 2 \mathrm{O}$ & $\mathrm{K} 2 \mathrm{O}$ & Ignition loss & Insoluble residue \\
\hline Cement & 64.83 & 21.34 & 5.79 & 2.75 & 2.85 & 1.66 & 0.19 & 0.64 & 0.59 & 0.25 \\
\hline Silica Fume & 0.49 & 93.6 & 1.23 & 0.87 & 0.97 & 0.1 & 0.31 & 1.01 & - & - \\
\hline
\end{tabular}

\subsubsection{Silica fume}

Non-condensing silica fume (micro silica) with light gray color produced by Ferro Aliage Iran Corporation was provided and used from Azna (chemical compositions according to Table 1).

\subsubsection{Colloid Nano-silica}

Two types of colloid Nano-silica produced by Eka Corporation with trade names of Cembinder 
8 and Cembinder 50 with specials planes of $80 \mathrm{~m}^{2} / \mathrm{gr}$ and $500 \mathrm{~m}^{2} / \mathrm{gr}$ were used. Due characteristics of used Nano-silica is illustrated in Table 2. Also another type of Nano-silica which is used to improve concrete permeability and mosaic production i.e. Beechems Colloidal Silica was provided and investigated thoroughly. Related information is illustrated in Table 2.

Table 2. Characteristics of Nano-silica under investigation

\begin{tabular}{|l|c|c|c|c|c|c|}
\hline & Size $(\mathrm{nm})$ & Type & Color & Surface Area $\left(\mathrm{m}^{2} / \mathrm{gr}\right)$ & $\mathrm{pH}$ & $\mathrm{SiO} \%$ \\
\hline Beechems (BC) & $>12$ & Colloidlal & White & - & 9 & 40 \\
\hline Eka Cembinder 8 (CEM8) & - & Colloidlal & White & 80 & 9.5 & 50 \\
\hline Eka Cembinder 50 (CEM50) & 5 & Colloidlal & Transparent & 500 & 9.7 & 15 \\
\hline Degussa Aerosil 90 (A90) & 20 & Powder & White & 90 & $3.7-4.7$ & 100 \\
\hline Degussa Aerosil 200 (A200) & 12 & Powder & White & 200 & $3.7-4.7$ & $>99.8$ \\
\hline Degussa Aerosil 380 (A380) & 7 & Powder & White & 380 & $3.7-4.7$ & $>99.8$ \\
\hline
\end{tabular}

\subsubsection{Powder Nano-silica}

Their types of powders i.e. Aerosil380, Aerosil200 and Aerosil90 with respective special plane of 90,200 and $380 \mathrm{~m}^{2} / \mathrm{gr}$ produced by Degussa Corporation were provided and used. Their due specifications and characteristics is illustrated in table 2 . Mostly these materials are used in dying industry.

\subsubsection{Super plasticizer}

GLENIUM 51P with polycarboxylic ether base produced by B.A.S.F Corporation was used in the study as super plasticizer.

\subsection{Mortar mixtures under the investigation}

Mortar mixtures investigated in this study include control mixture with water portion to cement (W/B) equal to $0 / 485$ and san portion to cement (Sand/B) equal to $2 / 75$. Performance rate evaluated based on measuring the amount of Ceylon (Flow) was $165 \%$. Mixtures containing silica fume and different types of Nano-silica with substitution values (S/B) of $0 / 5,1 / 5,3,5$, and 7 percent cement and with the same portion of sand to cement material, and water portion to cement material with control mixture were made. Performance rate for all mixtures were considered equal to control mixture and decline in performance was compensated with the use of silica fume and or Nano-silica by means of super plasticizer. Noteworthy is that regarding some mixtures despite of using super plasticizer up to $4 \%$ more than cement weigh, supposed performance was not achieved. So the related mixture was omitted from the list. Due information of mixtures is illustrated in table 4.

\subsubsection{How the mortars were mixed up?}

Concerning the importance of the distribution of fine particles in mortar, after preliminary steps and addition of all mixture ingredients the mortar was mixed up for 5 minutes with high speed circulation. For mixtures containing colloid Nano-silica, water and if necessary super plasticizer was added to the mixture. For powder Nano-silica and also silica fume the material was mixed up with water and if necessary with super plasticizer for 8 minutes to let the particles be distributed evenly in the mixture. Then other stages were followed to produce desired mortar as related other mixtures.

\subsubsection{Specimens}

Specimens were made ready in 12 (for times more than typical age) cubic format with $5 \mathrm{~cm}$ size. 
Table 3. Cement mortars pattern and the results of pressure resistance test

\begin{tabular}{|c|c|c|c|c|c|c|c|c|c|c|c|c|}
\hline \multirow{2}{*}{ Name } & \multirow{2}{*}{ Cement } & \multirow{2}{*}{$\mathrm{W} / \mathrm{B}$} & \multirow{2}{*}{$\mathrm{S} / \mathrm{B}$} & \multirow{2}{*}{$\mathrm{SP} / \mathrm{B}$} & \multirow{2}{*}{ SAND/B } & \multirow{2}{*}{ FLOW } & \multicolumn{3}{|c|}{ Strength (MPa) } & \multicolumn{3}{|c|}{ Strength ratio to control mix } \\
\hline & & & & & & & 7 days & 28 days & 56 days & 7 days & 28 days & 56 days \\
\hline Control & $100.00 \%$ & $48.20 \%$ & - & - & 2.75 & $168.5 \pm 5 \%$ & 38.8 & 48.9 & 54 & 1 & 1 & 1 \\
\hline MICRO-0.5 & $99.50 \%$ & $48.20 \%$ & $0.50 \%$ & $0.02 \%$ & 2.75 & $168.5 \pm 5 \%$ & 40.9 & 46.5 & 52.4 & 1.05 & 0.95 & 0.97 \\
\hline MICRO-1.5 & & & $1.50 \%$ & $0.06 \%$ & 2.75 & & 41.2 & 52 & 2.8 & 1.06 & 1.06 & 0.98 \\
\hline MICRO-3 & $7.00 \%$ & $48.20 \%$ & $3 \%$ & $0.08 \%$ & 2.75 & $168.5 \pm 5 \%$ & 39 & 54.1 & 56.9 & 1 & .11 & 1.05 \\
\hline MICRO-5 & $95.00 \%$ & $48.20 \%$ & $5 \%$ & $0.10 \%$ & 2.75 & $168.5 \pm 5 \%$ & 40.5 & 54.9 & 56.5 & 1.04 & 1.12 & 1.05 \\
\hline MICRO-7 & $93.00 \%$ & $48.20 \%$ & $7 \%$ & $0.12 \%$ & 2.75 & $168.5 \pm 5 \%$ & 39.3 & 55.66 & 57.7 & 1.01 & 1.14 & 1.08 \\
\hline CEM 8-0.5 & $99.50 \%$ & $48.20 \%$ & $0.50 \%$ & - & 2.75 & $168.5 \pm 5 \%$ & 37.3 & 47.31 & 50.49 & 0.96 & 0.97 & 0.93 \\
\hline CEM 8-1.5 & $98.50 \%$ & $48.20 \%$ & $1.50 \%$ & - & 2.75 & $168.5 \pm 5 \%$ & 37.66 & 47.19 & 54.69 & 0.97 & 0.97 & 1.01 \\
\hline $\mathrm{CE}$ & & 48.2 & $3 \%$ & $0.06 \%$ & 2.75 & & 41.7 & 49.27 & 55.55 & 1.07 & 1.01 & 1.03 \\
\hline $\mathrm{CE}$ & & $48.20 \%$ & $5 \%$ & $0.32 \%$ & 2.75 & & 44 & 52.99 & 55.79 & 1.13 & 1.08 & 1.03 \\
\hline $\mathrm{CEI}$ & $93.00 \%$ & $48.20 \%$ & $7 \%$ & $0.60 \%$ & 2.75 & $5 \%$ & 46.75 & 55.03 & 58.89 & 1.2 & 1.13 & 1.09 \\
\hline CEM & $99.50 \%$ & $48.20 \%$ & $0.50 \%$ & $0.10 \%$ & 2.75 & $168.5 \pm 5 \%$ & 41.1 & 52.15 & 56.64 & 1.06 & 1.07 & 1.05 \\
\hline CEM 5 & $8.50 \%$ & $48.20 \%$ & $1.50 \%$ & $1.70 \%$ & 2.75 & $5 \%$ & 45.41 & 50.2 & 52.45 & 1.17 & 1.03 & 0.97 \\
\hline CEM 50-3 & $97.00 \%$ & $48.20 \%$ & $3 \%$ & $3.70 \%$ & .75 & $168.5 \pm 5 \%$ & 46.3 & 54.93 & 57.2 & 1.19 & 1.12 & 1.06 \\
\hline & & & $0.50 \%$ & $0.10 \%$ & .75 & & 36.05 & 43.9 & 50.1 & 0.93 & 0.9 & 0.93 \\
\hline & & & $1.50 \%$ & & 2.75 & & 42.6 & 48.6 & 51.2 & 1.09 & 0.99 & 0.95 \\
\hline & & $48.20 \%$ & $3 \%$ & $2.04 \%$ & 2.75 & & 39.8 & 49 & 57.6 & 1.02 & & 1.07 \\
\hline BC -5 & $95.00 \%$ & $48.20 \%$ & $5 \%$ & $3 \%$ & 2.75 & $168.5 \pm 5 \%$ & 45.7 & 54.5 & 56.5 & 1.18 & 1.12 & 1.05 \\
\hline A90-0.5 & $99.50 \%$ & $48.20 \%$ & $0.50 \%$ & $0.10 \%$ & 2.75 & $168.5 \pm 5 \%$ & 39.1 & 47.4 & 52.9 & 1.05 & 0.97 & 0.98 \\
\hline A90-1.5 & $.50 \%$ & $48.20 \%$ & $1.50 \%$ & $0.32 \%$ & 2.75 & $\pm 5 \%$ & 39.5 & 47.4 & 52.2 & 1.02 & 0.97 & 0.97 \\
\hline A90-3 & & $48.20 \%$ & $3 \%$ & $0.50 \%$ & 2.75 & $168.5 \pm 5 \%$ & 40.9 & 47.9 & 52.8 & 1.05 & 0.98 & 0.98 \\
\hline & & 48. & $5 \%$ & $0.84 \%$ & 2.75 & & 45.1 & 50.2 & 52.7 & 1.16 & 1.03 & 0.98 \\
\hline & & & $7 \%$ & $1.30 \%$ & 2.75 & & 47.4 & 55.3 & 60.5 & 1.22 & 1.13 & 1.12 \\
\hline $\mathrm{A} 20$ & $.50 \%$ & $48.20 \%$ & $0.50 \%$ & $0.10 \%$ & .75 & 168 & 41 & 47.6 & 52.2 & 1.05 & 0.97 & 0.97 \\
\hline $\mathrm{A} 20$ & $3.50 \%$ & $48.20 \%$ & $1.50 \%$ & $0.72 \%$ & 2.75 & $168.5 \pm 5 \%$ & 41.7 & 47.5 & 50.2 & 1.07 & 0.97 & 0.93 \\
\hline A200-3 & $97.00 \%$ & $48.20 \%$ & $3 \%$ & $1.10 \%$ & 2.75 & $168.5 \pm 5 \%$ & 41.3 & 48.7 & 49.4 & 1.06 & 1 & 0.91 \\
\hline A200-5 & $5.00 \%$ & $48.20 \%$ & $5 \%$ & $2.00 \%$ & 2.75 & $168.5 \pm 5 \%$ & 44.5 & 53.3 & 52.7 & 1.14 & 1.09 & 0.98 \\
\hline A200-7 & $93.00 \%$ & $48.20 \%$ & $7 \%$ & $3.00 \%$ & 2.75 & $168.5 \pm 5 \%$ & 47.4 & 53.41 & 53.11 & 1.22 & 1.09 & 0.98 \\
\hline A380-0.5 & & $48.20 \%$ & $0.50 \%$ & $0.14 \%$ & 2.75 & $168.5 \pm 5 \%$ & 37.9 & 48.7 & 51.9 & 0.97 & 1 & 0.96 \\
\hline A380-1.5 & & $48.20 \%$ & $1.50 \%$ & $0.80 \%$ & 2.75 & $168.5 \pm 5 \%$ & 39.4 & 47.6 & 51.9 & 1.01 & 0.97 & 0.96 \\
\hline & & $48.20 \%$ & $3 \%$ & $1.60 \%$ & 2.75 & $55 \%$ & 37.4 & 47.8 & 52.7 & 0.97 & 0.98 & 0.97 \\
\hline A380-5 & $95.00 \%$ & $48.20 \%$ & $5 \%$ & $2.80 \%$ & 2.75 & $168.5 \pm 5 \%$ & 43.92 & 52.49 & 56.68 & 1.13 & 1.07 & 1.05 \\
\hline
\end{tabular}

\section{Results and discussions}

\subsection{Performance}

As it was mentioned in the previous section decline in mixtures' performance in contrast to control mixture was compensated with using super plasticizer. Therefore, the amount of needed super plasticizer to maintain the performance of mixtures containing Nano-silica particles and silica fume is regarded as an index of the impact of used materials on the performance of the mixtures.

As it can be seen in table 3 silica fume needs less amount of super plasticizer and even in 7 percent the needed super plasticizer does not exceed 925 of cement weigh. Application of colloid Nano-silica i.e. Cembinder 8 with special plane of $80 \mathrm{~m}^{2} / \mathrm{gr}$ in $5 \%$ usage impose 00000 impact over performanceality which is by using more Nano-silica the need for super plasticizer increases as in $7 \%$ usage of this material one needs to make use of $92 \%$ of super plasticizer. Therefore, Cembinder 50 Nano-silica with higher special plane in $3 \%$ usage needs $3 / 7 \%$ of super plasticizer which is more than normal amount and did not result in creation of mortar in more amounts than $3 \%$. For Beechems Nano-silica which is somehow bigger in size than Cembinder 50, in $5 \%$ usage $3 \%$ of super plasticizer is needed and using $7 \%$ of the same Nano-silica did not result in creation of desired mortar.

For three powders Nano-silica increasing their special plane decline of performanceality increased. For Aerosil 90 needed amount of super plasticizer in $7 \%$ usage was equal to $1 / 3 \%$. 
While this amount is accordingly $3 \%$ for the same amount of Aerosil 200 usage. For Aerosil 380 in $7 \%$ usage because of dramatic decline in performanceality the desired mortar could not be made.

\subsection{Pressure resistance}

The results of determination of pressure resistance for mortar mixtures are depicted in Table 3. To be able to have a better comparison, the impact of substitution of different amounts of Nano-silica and Micro-silica on mortar resistance, contributing results for each mixture as the ratio of pressure in each age to resistance of control mortar in the same age has been shown in Table 3. Also the results are illustrated in bar charts in Figs. 1-3 for ages of 7, 28, and 56. Results indicate that silica fume in 7 days does not impose effective impact on resistance. The most influential impact of silica fume on resistance increase happens in 28 days in $15 \%$ of usage. Increasing the amount of silica fume the effect of its usage on pressure increases either. For Nano-silica Cembinder 8 with special plane of $80 \mathrm{~m}^{2} / \mathrm{gr}$ pozzolanian performance and nucleation has been done faster and in 7 days $20 \%$ increase in contrast to control group can be seen. Increasing the amount of usage performance becomes better. It is interesting that as age grows the resistance declines in comparison to control group.

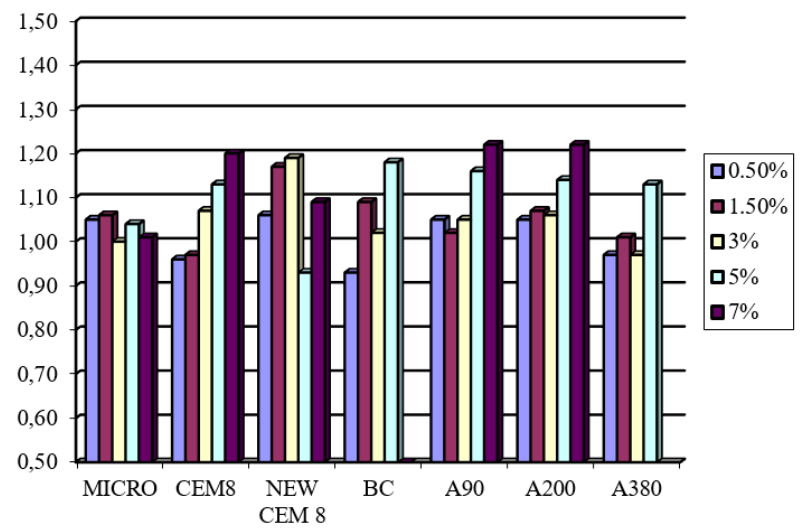

Fig. 1. The ratio of pressure resistance increase regarding different percentages of Micro and Nano-silica in 7 days

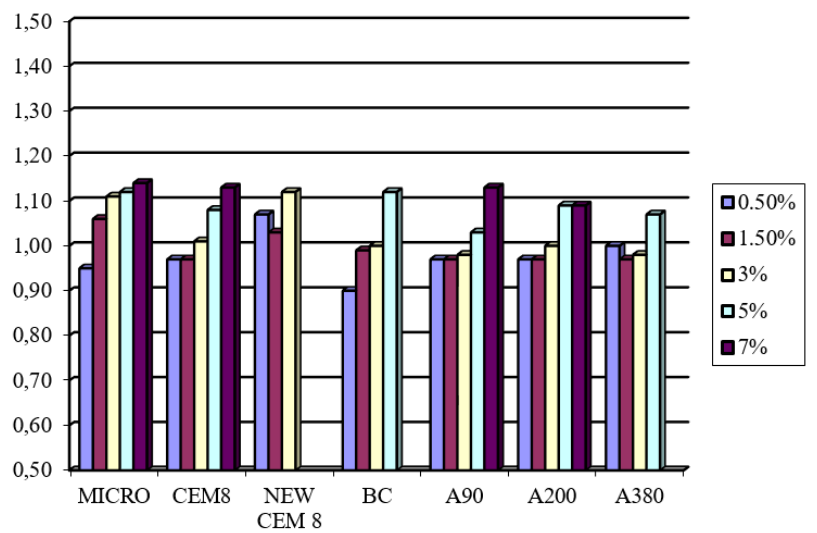

Fig. 2. The ratio of pressure resistance increase regarding different percentages of Micro and Nano-silica in 28 days 


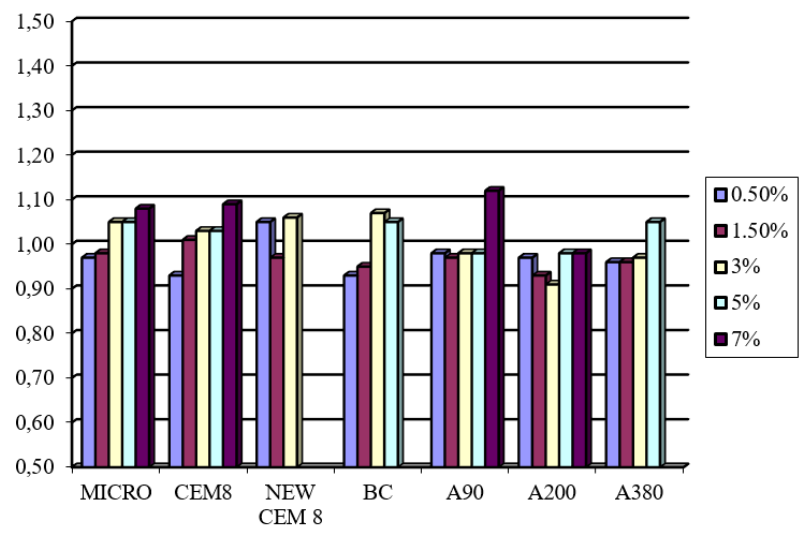

Fig. 3. The ratio of pressure resistance increase regarding different percentages of Micro and Nano-silica in 56 days

For other Nano-silica materials generally the most effective performance was observed in 7 days. Finer Nano-silica in lower amounts of usage show similar performance with bigger Nano-silica in higher amounts of usage.

\subsection{Examining the consumed Nano-silica and Micro-silica by means of Transmission Electron Microscopy (TEM)}

To examine the size of particles and their distribution stance or lump form TEM photography was done on diluted colloid Nano-silica Cembinder 8, Aerosil 200 powder Nano-silica and distributed Nano-silica fume in water. Fig. 4 shows related picture of silica fume powder grout in water. As it can be seen the size of particles is less than $50 \mathrm{~nm}$ to $500 \mathrm{~nm}$. In Fig. 5 related picture for Cembinder 8 colloid Nano-silica is presented which shows that its particles are finer that silica fume.

In Fig. 6, Aerosil 200 Nano-silica powder in water is presented. As it can be seen particles are in grout stance. Therefore, particles are attached together and made grouts and also they are finer than individual particles of Cembinder 8. It is obvious that the size and distribution stance of particles vary in greater areas.

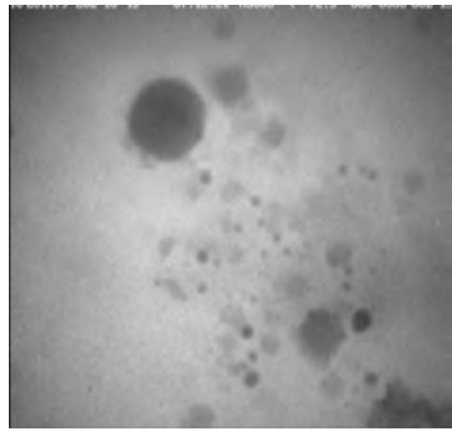

Fig. 4. Silica Fume

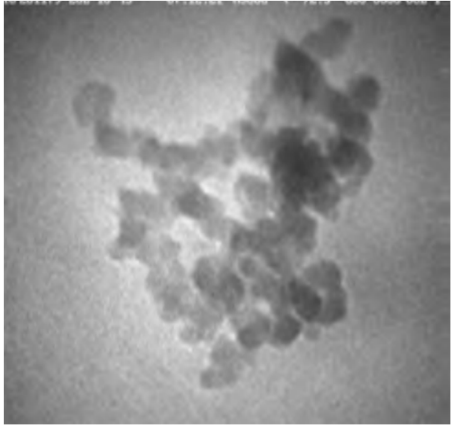

Fig. 5. Cembinder 8

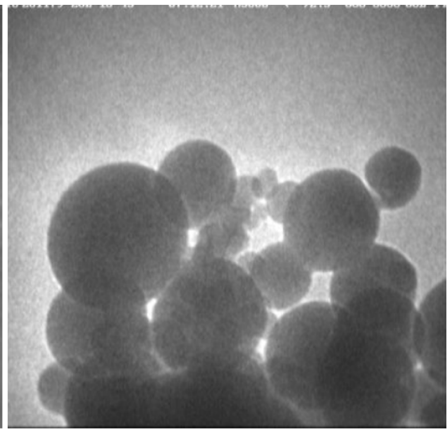

Fig. 6. Aerosil 200

\section{Conclusions}

The impact of Nano-silica materials in decreasing the performance of mixtures is more than silica fume. With increasing the special plane capability of Nano-silica we can observe more decrease in performance in the way that for Nano-silica with the maximum special plane we could not succeed making desired mortar in more than $3 \%$ usage. 
The maximum impact of Nano-silica materials on resistance in comparison to control mixture was seen in 7 days. With increasing the amount of Nano-silica usage the improvement of resistance increases.

Increase in age results in gradual decrease in improvement of resistance of mixtures with Nano-silica than control mixture. In most cases the rate of improvement in resistance in 56 days is not significant in comparison to control mixture.

According to TEM evaluations used Nano-silica would pertain to different characteristics including particle size and grout stance in distribution.

\section{References}

[1] Shih J., Chang T., Hsiao T. Effect of Nano-silica on characterization of Portland cement composite. Materials Science and Engineering, Vol. 424, 2006, p. 266-274.

[2] Lin D. F., Lin K. L., Chang W. C., Luo H. L., Cai M. Q. Improvements of nano-SiO2 on sludge/fly ash mortar. Waste Management, Vol. 28, 2008, p. 1081-1087.

[3] Jo B., Kim C., Tae G., Park J. Characteristics of cement mortar with nano-Si02 particles. Construction and Building Materials, Vol. 21, 2007, p. 1351-1355.

[4] Li H., Xiao H., Ou J. A study on mechanical and pressure-sensitive properties of cement mortar with nanophase materials. Cement and Concrete Research, Vol. 34, 2004, p. 435-438.

[5] Sadrmomtazi A., Fasihi A., Balalaei F., Haghi A. Investigation of mechanical and physical properties of mortars containing silica fume and NanoSiO2. Proceedings of the 3rd International Conference on Concrete and Development, Tehran, 2008, p. 1163-1161.

[6] Li H., Zhang M., Ou J. Abrasion resistance of concrete containing nano-particles for pavement. Wear, Vol. 260, 2006, p. 1262-1266. 